\title{
Critical Factors Determining Adoption of Telemedicine
}

\author{
https://doi.org/10.3991/ijoe.v15i11.10492 \\ Yousif Salim Abdalla \\ University of Khartoum, Khartoum, Sudan \\ datsunii@yahoo.co.uk
}

\begin{abstract}
Health service is a very complex and expensive public service and it is a highly sensitive service that highly determines the human capital besides knowledge. In this study we used six technology dimensions (product design, patient relationship management, supply chain management, knowledge management, environment, and governance structure), that highly determine an effective adoption of telehealth health care service. We used DNAP model (DEMATEL and ANP) to evaluate and prioritize the weights of the factors that influence an investment in telemedicine health care service. The results of this study show that product design and patient relationship management has a higher interaction with the rest of the selected dimensions such as knowledge management, supply chain management, governance, and environment. Within the product design with respect to the rest of the dimensions, behavioral requirement ranks first, next knowledge requirement, and third technology requirement; patient relationship management with respect to the rest of the dimensions, the ranking is: social network ranks first, next patient service, and third empowerment.
\end{abstract}

Keywords-Telemedicine, ANP, DEMATEL, Knowledge management

\section{Introduction}

With growing population and the corresponding pressures on basic services, public investment and its social and economic viability tradeoffs is crucial for governments and public institutions to prioritize the most urgent dimensions of these services. Human health is the most critical and sensitive issue for sustainable development and life continuation. In this regard, Telemedicine has become the most promising solution to the complex problems of the healthcare industry. Therefore, to expand access to health services for a large number of populations given the limited human and financial resources, it is imperative to identify the key driving forces that influence the adoption of telemedicine and their relative influencing weights so that investments are prioritized based on feasible options. Telemedicine (Tm) is multidisciplinary in nature. We proposed six dimensions namely product design, patient relationship management, supply chain management, knowledge management, environment, and governance structure.

This paper is organized as follows: Section 2 include definition of Tm, Section 3 includes literature review, Section 4 contains Tm adoption description, sections 5 and 
6 descriptions of DEMATEL and ANP, section 7 application of DNAP and results analyses, section 8 conclusion.

\section{Definition of Telemedicine}

Here we use the WHO definition [1]: "The delivery of health care services, where distance is a critical factor, by all health care professionals using information and communication technologies for the exchange of valid information for diagnosis, treatment and prevention of disease and injuries, research and evaluation, and for the continuing education of health care providers, all in the interests of advancing the health of individuals and their communities".

\section{$3 \quad$ Literature Review}

Telemedicine applications cover a number of areas such as teleradiology (teleneurology and telecardiology), teledermatology, Telewoundcare, telepysychiatry, telemental health, Teleopthalmology, TeleENT (Teleotolaryngology), Telpaediatrics, TeleObsterics (Fetal Telemedicine), Teleoncology, Telegeriatrics, Telehome care [2]. The effeteness and efficiency of these applications have been evaluated by many authors such Abdulmajid Asiri et al [3], Hoe Tung Yes et al [4], Sandra da Silva Mattos et al [5], and many others.

\section{$4 \quad$ Telemedicine Adoption Roadmap}

\subsection{Product / service design}

For product/service design the quality function deployment (QFD) has been used. The QFD [9] describes the whole process of product design requirements by translating customer requirements into appropriate technical requirements for each stage of the product development and production. It employs the house of quality (HOQ), which is presented by a matrix describing the relationship between customer requirements and product functions or characteristics. Chan and $\mathrm{Wu}[9]$ organized four stages including translating the customer requirements into technical measures, the technical measures into parts characteristics, the parts characteristics into process operations, and the process operations into day-to-day production requirements. In the health industry, for instance, Antoniac et al [10] used QFD model for the design and development of mobile services platform for senior citizens. Mr. Salahuddin [11] used QFD for wearable technology product development. Margherita Peruzzini and Michele Germani [12] applied the model of QFD for designing a user-centered ICT platform for active aging. Shih and Chen [13] applied the hybrid model QFD-TRIZ supported by analytic network process (ANP) mode in their conceptual design of a mobile-healthcare-device. 


\subsection{Behavioral requirement}

Expected values: These values are those we can easily understand and convey them verbally. Both the patient and the designer can easily exchange these requirements verbally. To address the behavioral dimension for accepting Tm technologies some behavioral models have been used, i.e., such as TAM 1 and TAM 2 were used. These studies do not consider the concept of self-efficacy [14]. Bandura [15] in his 'social learning theory', although individuals learn through observational behavior and symbolic modeling, the effects of these observational learning and symbolic modeling do not necessarily result into desired behavior. Because individuals may retain the behavioral model but are unmotivated to translate it into action if appropriate reinforcement tools are not provided. These tools can be incentives or rewards that guarantee responses to the desired behavior [16].

\subsection{Supply chain management}

SCM has been discussed within the business model of an organization to align its business processes with technology-driven organizations-networked business processes and to establish strategic alliances with varying actors (such as suppliers, channel partners, and service providers) seeking synergies, minimizing costs, and maximizing shared benefits in IT-based business collaboration [17]. Some examples of the ITbased business networks are: teleworking model, the virtual organization model, the collaborative product development model, the process outsourcing model, and the value-chain integrated model. The integrated value-chain model describes an integrated business interaction between actors of common interest such clients/consumers, distributers, and producers in virtual settings [18]. There are three approaches to this integrated business process:

- The global business approach

- The multiple homogenous process approach

- The multiple heterogeneous approaches [18]

The virtual enterprise has following functionalities:

Basic information exchange interaction: This supports exchange of shared/public commercial data such as contract-related interactions, technical data such as product models and quality information, general information such as market statistics and catalogues of products/services, etc.

Events / exception handling: This supports asynchronous events and exceptions generated inside the company or by other nodes in the network.

Advanced coordination: This supports coordination via the VE coordinator which is responsible for monitoring the job status.

Material / services related aspects: This supports monitoring the flow of products/services through the VE network. 


\subsection{Patient relationship management}

Customer relationship management concept is a pervasive technology-based business process. Typically, CRM is well modeled at the system level to ensure compatibility and operability of each portion of transaction that posits an interaction between customers and service providers and within the internal business of an organization. Alt et al [19] described the customer processes with portal services, and the system architecture guideline that integrates the CRM with other related business processes systems. Customer relationship management has been further developed by the use of CRM 2, which is a typical social networking interaction between communities and individuals. Social customer relationship management has been a slogan for e-health organizations [20]. The CRM 2 (as extended from CRM1) is based on Web 2. It establishes relationships between healthcare provider, patients, public, and social networks. It provides better understanding of patient's preferences, and enables patients and provider to generate contents.

\subsection{Knowledge management capability}

$\mathrm{KMC}$ is central in positioning the organizational overall capability and it includes three dimensions - technology, structure, and culture; and the knowledge management process includes knowledge creation, sharing, storage, and application. Technology, structure, and culture are key concepts in knowledge management process [20]. Technological capabilities include: such as application of software and hardware systems, learning tools, simulation models, concept mapping systems, artificial intelligence, etc. Structural capabilities include communities of practice, internet, intranet, extranet, R\&D, KM Groups, KPI for measurement of knowledge management capabilities, etc. Cultural capabilities include awareness, valuation for innovation, adventurism, diversified cultural and international outlook, proactive attitudes, etc. Knowledge taxonomy - The well known knowledge taxonomies are tacit knowledge and explicit knowledge. Tacit knowledge is a knowledge rooted in actions, experience, and involvement in specific context; Cognitive tacit knowledge include mental models whereas the technical tacit is a know-how applicable to specific work (skills); explicit knowledge is an articulated, generalized knowledge.

\subsection{Governance}

Rodgers et al [21] defined governance structure as: Governance structure is in fact a structure regulating exchange, which articulates a direction mechanism, control procedures and an incentive system with respect to the terms of contract".

Regulating exchange: This exchange deemed to be inclusive or exclusive of all concerned actors with varying importance weights.

A direction mechanism: This refers to whose role is more important than others (political implications).

Control procedures: Control procedures refers to accountability, feedback, evaluation, and redesign. 
Incentive system and contract: This highlights balancing between quality, costs, and compliance.

Until now there are few contributions to the concept of governance in Tm. Some focused on the system level governance that includes state, healthcare system and healthcare institutions, partnership governance, the issues of accountability, quality standards and ethics [22]. Mort et al [23] focused on the patient level of governance, where telepatient's identity is the core for governance of telehealth care. Tm is ICTbased healthcare service where telehealth patients play a key role for the success of this service they are deemed as active players in the service design process, selfmanagers in the application, intelligence providers in the evaluation, and revenue generators/fees/tax payers in providing sustainable and innovative acceptable quality health care services.

\subsection{Environment}

External factors are critical requirements and play a crucial role in successful implementation of Tm healthcare services. These include:

- Communication technology infrastructure

- Supporting infrastructures

- Nature of market

- Stakeholders support

- Policy/regulation/rules.

Technology infrastructures include wireless and wired communication networks [Tulu et al, 2005].

Supporting infrastructures include physical locations of hospitals, clinical health centers, patient level platforms, electricity infrastructures, etc.

Nature of market is a critical condition for Tm adoption [24]. Size of the market and market segments of key users provide an economic feasibility base for the implementation of the Tm.

Stakeholder support is a key to sustainable Tm services [24]. Stakeholders are sources of funding including private and public sectors, and patients/patient families.

Policies that support adoption of Tm and rules/regulations that set standards and procedures are vital for sustainable continuity of the Tm healthcare services.

\section{Dematel}

Referring to the work of Ali Taghizadeh Herat et al [25], DEMATEL method was introduced by BMI Institute, Swiss, between 1972 and 1976, in a project in Geneva Research Center to examine and solve complicated problems (Moghadam and Alavijeh, 2009). [26]. Tsai and Chou [40] employed DEMATEL approach to construct interrelations between criteria that SMEs require to evaluate a quality management system. Wu [41] also used DEMATEL to evaluate interrelationship between influen- 
tial factors in assessing knowledge management strategies in Taiwan organizations. The steps in DEMATEL are as follows:

Step 1: Derivation of the average matrix - in our study we have used 5 experts (P) who were asked to assign a value to the influence of criterion $i$ on criterion $j$ as denoted by $\alpha \mathrm{ij}$ from a range of influence values ranging from 0 to 4 (from no influence to very high influence respectively). The values assigned by the experts are represented by $\mathrm{n} \mathrm{n}$ non-negative matrix Xk $=[\mathrm{xkij}] \mathrm{nxn}$, with $1 \leq \mathrm{k} \leq \mathrm{P} . \mathrm{X} 1, \mathrm{X} 2, \ldots$, XP are the resulting matrices for each expert of the $\mathrm{P}$ experts, and each element of $\mathrm{Xk}$ is an integer represented by xkij. The diagonal elements of matrix Xk represent influence of criterion $i$ on $i$ and criterion $j$ on $j$ and are set to zero. Then, the average matrix A, which is called the initial direct relation matrix, is calculated as:

$$
\mathrm{A}=\left[\alpha_{\mathrm{ij}}\right]_{\mathrm{nxn}}=1 / \mathrm{P} \sum_{\mathrm{k}=1}^{\mathrm{P}}\left[\mathrm{x}_{\mathrm{ij}}^{\mathrm{k}_{\mathrm{ij}}}\right]_{\mathrm{nxn}}
$$

Step 2: Derivation of the normalized direct relation matrix denoted by D from matrix A:

$$
\begin{gathered}
\text { Letting } \mathrm{s}=\max \left(\max _{1 \leq \mathrm{i} \leq \mathrm{n}} \sum_{\mathrm{j}=1}^{\mathrm{n}_{\mathrm{j}}} \alpha_{\mathrm{ij}}, \max _{1 \leq \mathrm{j} \leq \mathrm{n}} \sum_{\mathrm{i}=1}^{\mathrm{n}_{1}} \alpha_{\mathrm{ij}}\right) \\
\text { Then, } \mathrm{D}=\mathrm{A} / \mathrm{s}
\end{gathered}
$$

The sum of each row of matrix 'A' represents the total direct effects of criterion $\mathrm{i}$ on the 'js' criteria along the columns. Likewise, the sum of each column of matrix A represents the effects received from the 'is' criteria. Therefore, $\max _{1 \leq i \leq n} \sum_{\mathrm{j}=1}^{\mathrm{n}_{1}} \alpha_{\mathrm{ij}}$, and $\max 1 \leq \mathrm{j} \leq \mathrm{n} \sum^{\mathrm{n}_{\mathrm{i}=1}} \alpha_{\mathrm{ij}}$ represent the maximum effects dispatched and received between $\mathrm{i}$ and $\mathrm{j}$ criteria respectively. Each element $\mathrm{d}_{\mathrm{ij}}$ of matrix A falls between zero and less than 1.

Step 3: Computation of the total relation matrix: According to Markov chain matrix, $\lim _{\mathrm{m} \rightarrow \infty} \mathrm{D}^{\mathrm{m}}=[0]_{\mathrm{nxn}}$ and $\left(\mathrm{I}+\mathrm{D}^{1}+\mathrm{D}^{2}+\mathrm{D}^{3} \ldots+\mathrm{D}^{\mathrm{m}}\right)=(\mathrm{I}-\mathrm{D})^{-1}$, where 0 is nxn null matrix and $\mathrm{I}$ is the nxn identity matrix. The total relation matrix is an nxn matrix and is represented by:

$$
\mathrm{T}=\left[\mathrm{t}_{\mathrm{ij}}\right], \mathrm{i}, \mathrm{j}=1,2, \ldots \mathrm{n}
$$

From the T matrix we can then derive the effects and causal relations between the criteria as follows:

$$
\mathrm{r}=\left[\mathrm{r}_{\mathrm{i}}\right]_{\mathrm{nx} 1}=\left(\sum_{\mathrm{j}=1}^{\mathrm{n}_{\mathrm{j}}} \mathrm{t}_{\mathrm{ij}}\right)_{\mathrm{n} \times 1}
$$

Where $r_{i}$ denotes the total effects direct and indirect dispatched by criteria 'is' on criteria 'js'

$$
\mathrm{c}=\left[\mathrm{c}_{\mathrm{j}}\right]^{\prime}{ }_{1 \times n}=\left(\sum_{\mathrm{i}=1}^{\mathrm{n}_{1}} \mathrm{t}_{\mathrm{ij}}\right)_{1 \times n}
$$

Where the subscript (') represents the transpose and $c_{j}$ denotes the total effects received by criteria 'js' from criteria 'is' both direct and indirect. Therefore, $\left(r_{i}+c_{j}\right)$ and $\left(r_{i}-c_{j}\right)$ denote the total effects 'dispatched and received' and the net effect of 'dispatched and received' respectively. When the net effect of a criterion is positive, then 
this criterion is classified with cause group, whereas the net effect of a criterion is negative, then this criterion is classified with effect group [27].

Step 4: Obtaining the network relationship map (NRM) by setting a threshold value. The threshold value (which is normally determined by the experts) is the minimum value that is acceptable in the T matrix where any value below this threshold is considered negligible. NRM is derived from the normalized T matrix. The NRM will determine the inner and outer dependencies that will be considered in the ANP procedures [28].

\section{Analytic Network Process (ANP)}

The ANP, a new theory extending from the AHP, is proposed by Saaty (1996). AHP model contains hierarchical relationship between overall goal, criteria, subcriteria and alternatives. However the problems do not always show hierarchical structure. In such a case, ANP structures the problem as network instead of hierarchical modeling. However in ANP, criteria in the lower level may provide feedback to the criteria in the higher level, and the interdependence among the criteria in the same level is permitted. Another difference between AHP and ANP in the calculation process is that a new concept "super-matrix" is introduced in ANP. The application steps of ANP which is composed of four major steps are as follows (Saaty, 1999):

Step 1: Forming the network structure

The problem should be stated clearly and decomposed into a rational system like a network. The structure can be obtained by the opinion of decision-makers through brainstorming or other appropriate methods. Firstly, criteria, sub criteria and alternatives are defined. Then, the clusters of elements are determined. Network is formed based on the relationship between clusters and within elements in each cluster [29].

Step 2: Forming pair-wise comparison matrices and obtaining the priority vector Pair-wise comparisons are performed on the elements within the clusters as they influence each cluster and on those that it influences, with respect to that criterion. The pair-wise comparisons are made with respect to a criterion or sub-criterion of the control hierarchy. Thus, importance weight of factors is determined. In pair-wise comparison, decision makers compare two elements. Then, they determine the contribution of factors to the result (Saaty, 2001). In ANP, like AHP, it is formed pair-wise comparison matrices with use 1 to 9 scale of relative importance proposed by Saaty (1999). 1 to 9 scale of relative importance is given in Table 1.

Table 1. Scale of relative importance

\begin{tabular}{|l|l|l|l|l|l|}
\hline \multicolumn{1}{|c|}{$\mathbf{1}$} & \multicolumn{1}{c|}{$\mathbf{3}$} & \multicolumn{1}{c|}{$\mathbf{5}$} & \multicolumn{1}{c|}{$\mathbf{7}$} & \multicolumn{1}{c|}{$\mathbf{9}$} & \multicolumn{1}{c|}{$\mathbf{2 , \mathbf { 6 , 8 }}$} \\
\hline $\begin{array}{l}\text { Equal } \\
\text { importance }\end{array}$ & $\begin{array}{l}\text { Moderate im- } \\
\text { portance }\end{array}$ & $\begin{array}{l}\text { Strong im- } \\
\text { portance }\end{array}$ & $\begin{array}{l}\text { Very strong } \\
\text { importance }\end{array}$ & $\begin{array}{l}\text { Extreme } \\
\text { importance }\end{array}$ & $\begin{array}{l}\text { Intermediate value between } \\
\text { adjacent scale values }\end{array}$ \\
\hline
\end{tabular}

A reciprocal value is assigned to the inverse comparison; that is $a_{i j}=1 / a_{j i}$ where $a_{i j}$ and $\mathrm{a}_{\mathrm{ji}}$ denote the importance of the ith and jth elements. Like AHP, The values of 
pair-wise comparisons are allocated in the comparison matrix and local priority vector is obtained from eigenvector, which is calculated from this equation:

$$
\mathrm{A} \times \mathrm{W}=\lambda_{\max } \mathrm{x}
$$

Where $\mathrm{A}$ is the matrix of the pair-wise comparison, $\mathrm{W}$ is the eigenvector, and $\lambda_{\max }$ is the largest eigenvalue of A. Consistency of pair-wise matrix is checked by consistency ratio (CR). For accepted consistency, CR must be smaller than 0.10 (Saaty, 2005).

$$
\mathrm{CI}=\left(\lambda_{\max } \mathrm{x}-\mathrm{n}\right) / \mathrm{n}-1, \mathrm{CR}=\mathrm{CI} / \mathrm{RI}
$$

$\mathrm{CI}$ is consistency index and RI is random index which is selected from a range of random index values as shown in Table 2.

Table 2. Random index

\begin{tabular}{|c|c|c|c|c|c|c|c|c|c|c|c|c|c|c|c|}
\hline $\mathbf{n}$ & $\mathbf{1}$ & $\mathbf{2}$ & $\mathbf{3}$ & $\mathbf{4}$ & $\mathbf{5}$ & $\mathbf{6}$ & $\mathbf{7}$ & $\mathbf{8}$ & $\mathbf{9}$ & $\mathbf{1 0}$ & $\mathbf{1 1}$ & $\mathbf{1 2}$ & $\mathbf{1 3}$ & $\mathbf{1 4}$ & $\mathbf{1 5}$ \\
\hline $\mathrm{RI}$ & 0 & 0 & 0.58 & 0.90 & 1.21 & 1.24 & 1.32 & 1.41 & 1.45 & 1.49 & 1.51 & 1.53 & 1.56 & 1.57 & 1.59 \\
\hline
\end{tabular}

Step 3: Supermatrix formation - For evaluating the weights of elements, the AHP uses the principal eigenvector of the comparison matrix, while the ANP employs the limiting process method of the powers of the super-matrix. The super-matrix concept is similar to the Markov chain process (Saaty, 2005). To obtain global priorities in a system with interdependent influences, the local priority vectors are entered in the appropriate columns of a matrix. As a result, a super-matrix is actually a partitioned matrix, where each sub-matrix represents a relationship between two nodes (components or clusters) in a system. Each sub-matrix is multiplied by a corresponding element of the T-matrix (after normalization) that is defined above.

\section{$7 \quad$ Application of The DANP and Results Analyses}

\begin{tabular}{|c|c|c|c|c|}
\hline Dimension & & Criteria & & Description \\
\hline \multirow[t]{3}{*}{$\begin{array}{l}\text { Product service } \\
\text { design }\end{array}$} & PD & $\begin{array}{l}\text { Technology require- } \\
\text { ment }\end{array}$ & TR & Hardware and software technology \\
\hline & & $\begin{array}{l}\text { Knowledge require- } \\
\text { ment }\end{array}$ & KR & Tacit and explicit knowledge \\
\hline & & $\begin{array}{l}\text { Behavioral require- } \\
\text { ment }\end{array}$ & BR & Expectancies and incentives \\
\hline \multirow[t]{5}{*}{$\begin{array}{l}\text { Supply chain } \\
\text { management }\end{array}$} & $\mathrm{SCM}$ & $\begin{array}{l}\text { Basic information } \\
\text { exchange interaction }\end{array}$ & BIE & $\begin{array}{l}\text { e.g. contract-related interactions, product models, } \\
\text { quality information, market statistics, etc. }\end{array}$ \\
\hline & & $\begin{array}{l}\text { Events/exceptions } \\
\text { handling }\end{array}$ & EVC & Asynchronous events and exceptions \\
\hline & & Advanced coordination & $\mathrm{AC}$ & Monitoring job status \\
\hline & & \begin{tabular}{|l|} 
Material/services \\
aspects
\end{tabular} & MSP & $\begin{array}{l}\text { Monitoring materials/services flow, logistics plan- } \\
\text { ning, forecasting, bar coding and POS }\end{array}$ \\
\hline & & Collaborative envi- & CLL & Concurrent engineering, problem solving, consul- \\
\hline
\end{tabular}

Table 3. Dimensions and criteria descriptions 


\begin{tabular}{|l|l|l|l|l|}
\hline & & ronment & & tancy \\
\hline Environment & EN & ICT infrastructure & ICT & Wireless and wired communication n networks \\
\hline & & $\begin{array}{l}\text { Supporting infrastruc- } \\
\text { tures }\end{array}$ & SI & $\begin{array}{l}\text { Hospitals, clinical health centers, patient level } \\
\text { health platforms, electricity, etc }\end{array}$ \\
\hline & & Nature of market & NM & Size of market, market segments characteristics \\
\hline & Stakeholder support & SS & $\begin{array}{l}\text { Public sectors, private sectors, patients, patients } \\
\text { families, nurses, doctors, etc }\end{array}$ \\
\hline Governance & GS & Regulating exchange & RE & $\begin{array}{l}\text { Inclusive and exclusive procedures for concerned } \\
\text { actors }\end{array}$ \\
\hline & & Direction mechanisms & DM & Power share among key stakeholders \\
\hline & & Control procedures & CP & Accountability, feedback, evaluation and redesign \\
\hline $\begin{array}{l}\text { tutient relation- } \\
\text { ship management }\end{array}$ & RPM & Patient services & PS & $\begin{array}{l}\text { Prevent services, feel unwell services, fall ill ser- } \\
\text { vices, treatment services }\end{array}$ \\
\hline & & Marketing & M & $\begin{array}{l}\text { Market screening, - market segments, patient needs, } \\
\text { market size, market demand status }\end{array}$ \\
\hline & & Social networking & SN & Use of CRM2 \\
\hline Empowerment & EM & $\begin{array}{l}\text { Decision making - personal data management, } \\
\text { participation in prescription, etc }\end{array}$ \\
\hline
\end{tabular}

Five experts were involved in identifying key dimensions and criteria for adopting the Tm. The study data collection and analyses are as follows:

Using a questionnaire five experts were asked to assign relative influence value to each dimension (ranging from 0 (no influence) to 4 (very high influence). This results to the construction of an average initial direct relation matrix as shown in Table 4.

Table 4. Initial direct relation matrix

\begin{tabular}{|l|c|c|c|c|c|c|}
\hline & PD & CRM & KM & GS & EN & SCM \\
\hline PD & 0 & 4 & 0 & 0 & 0 & 0 \\
\hline CRM & 4 & 0 & 2.5 & 0 & 0 & 2.5 \\
\hline KM & 4 & 4 & 0 & 2.5 & 0 & 4 \\
\hline GS & 3 & 3 & 3.5 & 0 & 0 & 0 \\
\hline EN & 4 & 3 & 3 & 2 & 0 & 3 \\
\hline SCM & 4 & 3 & 3 & 0 & 0 & 0 \\
\hline
\end{tabular}

Table 5. Cause and Effect relationship

\begin{tabular}{|l|c|c|c|c|c|c|}
\hline & PD & PRM & KM & GS & EN & SCM \\
\hline PD & 0.068 & 0.240 & 0.0389 & 0.005 & 0 & 0.039 \\
\hline CRM & 0.322 & 0.140 & 0.184 & 0.024 & 0 & 0.189 \\
\hline KM & 0.403 & 0.390 & 0.124 & 0.148 & 0 & 0.288 \\
\hline GS & 0.294 & 0.289 & 0.242 & 0.0319 & 0 & 0.089 \\
\hline EN & 0.424 & 0.369 & 0.274 & 0.141 & 0 & 0.264 \\
\hline SCM & 0.339 & 0.292 & 0.215 & 0.0283 & 0 & 0.084 \\
\hline
\end{tabular}


Table 6. Cause and Effect relationship

\begin{tabular}{|l|c|c|c|c|}
\hline & $\mathbf{R}$ & $\mathbf{C}$ & $\mathbf{R}+\mathbf{C}$ & R-C \\
\hline PD & 0.392 & 1.850 & 2.242 & -1.458 \\
\hline PRM & 0.860 & 1.722 & 2.582 & -0.861 \\
\hline KM & 1.353 & 1.078 & 2.431 & 0.275 \\
\hline GS & 0.947 & 0.379 & 1.326 & 0.568 \\
\hline EN & 1.472 & 0.000 & 1.472 & 1.472 \\
\hline SCM & 0.958 & 0.954 & 1.912 & 0.005 \\
\hline
\end{tabular}

$(\mathrm{R}+\mathrm{C})$ denotes to prominence of dimension. The highest prominence dimension is patient relationship management (PRM) with coefficient of 2.582. Next is knowledge management (KM) with coefficient of 2.431. (R-C) represents net influence. This classifies the dimensions into cause and effect groups with positive and negative signs respectively. Among the cause group, environment is prominent with a coefficient of 1.472 whereas governance structure (GS) is next with coefficient of 0.568 . Among the effect group, product design (PD) is prominent with a coefficient of -1.458 . Next is PRM with a coefficient of -0.861 . Both PD and PRM are the only effect group

Table 7. The normalized $\mathrm{T}^{\mathrm{N}}$-matrix at threshold value $>.20$

\begin{tabular}{|l|c|c|c|c|c|c|}
\hline & PD & PRM & KM & GS & EN & SCM \\
\hline PD & 0 & 1 & 0 & 0 & 0 & 0 \\
\hline PRM & 1 & 0 & 0 & 0 & 0 & 0 \\
\hline KM & 0.372590064 & 0.361007343 & 0 & 0 & 0 & 0.266402593 \\
\hline GS & 0.355655602 & 0.35096239 & 0.293382008 & 0 & 0 & 0 \\
\hline EN & 0.318424773 & 0.277130931 & 0.205987387 & 0 & 0 & 0.198456909 \\
\hline SCM & 0.400956022 & 0.345284064 & 0.253759914 & 0 & 0 & 0 \\
\hline
\end{tabular}

PD and PRM influence each other only with equal influence on each other with a weight of $1(100 \%)$. SCM influences PD most among the rest with a weight of 0.4009 (40.10\%). KM is next most influential dimension with a weight influence of $37.26 \%$ on PD and $36.10 \%$ on PRM. Figure 1 shows the derived NRM. The influence within each dimension is zero for all dimensions implying that there is no inner dependence within each dimension. 


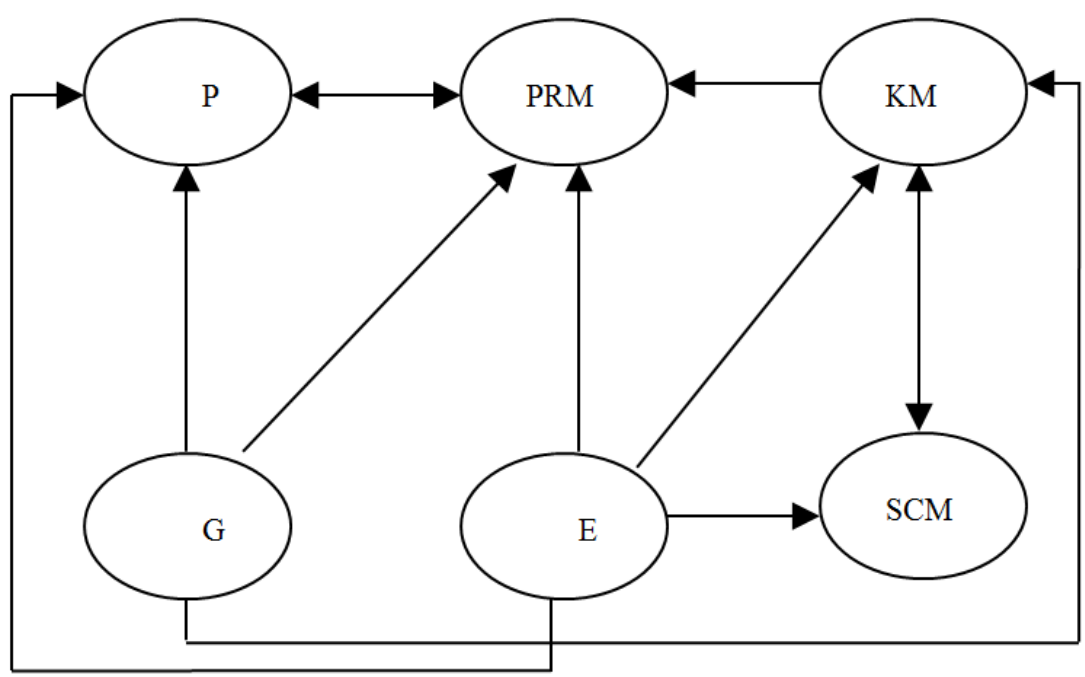

Fig. 1. NRM

The NRM determines the relationship within each dimension and among dimensions in the construction of the ANP-Supermatrix. The five experts also assigned relative importance value (Table 1) to each pair of criteria under each dimension. For instance, under dimension product design (PD) with respect to patient relationship management (PRM) we have the following pair-wise comparison between criteria resulting to an ANP sub-matrix:

Table 8. Average - With respect to PS (patient service)

\begin{tabular}{|l|c|c|c|c|c|}
\hline & BR & KR & BR & Eigen vectors & Consistency ratio (CR) $<0.10$ \\
\hline TR & 1 & 3 & 5 & 0.633 & \multirow{2}{*}{0.062} \\
\cline { 1 - 5 } KR & 0.333 & 1 & 3 & 0.260 & \\
\hline BR & 0.20 & 0.333 & 1 & 0.106 & \\
\hline
\end{tabular}

The process of pair-wise comparison is done with respect to each criterion under PRM. The same process is done for all the criteria under their relative dimensions. However, this is done based on the results of relationships of NRM shown in Table 7. 
Table 9. Limited matrix

\begin{tabular}{|c|c|c|c|c|c|c|c|c|c|c|c|c|c|c|c|c|c|c|c|c|c|c|c|c|c|}
\hline & 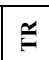 & & & & & n & $1=$ & & & & & & & & & & & & in & $\frac{\bar{x}}{\underline{\underline{N}}}$ & $\underline{\underline{y}}$ & \begin{tabular}{|l|}
\multirow{r}{*}{} \\
\end{tabular} & & & \\
\hline$\simeq$ & g & & & & & & & & & & & & & & & & $\approx$ & & 7 & & $\frac{7}{0}$ & $\frac{9}{0}$ & I & & \\
\hline & 8 & & & & & & & & & & & & & & & & & $\stackrel{m}{0}$ & $\stackrel{m}{0}$ & 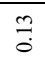 & & \begin{tabular}{|l|} 
\pm \\
\end{tabular} & \pm & & \\
\hline $\bar{\infty}$ & & & & & & & & & & & & & & & & & & 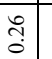 & \. & జ్రి & స్త & $\bar{a}$ & సิ & \begin{tabular}{|c|} 
\\
0
\end{tabular} & \\
\hline$\stackrel{\infty}{2}$ & $\tilde{z}$ & & & g & & & & & & & & & & & & & 5 & $=$ & $\bar{F}$ & ב. & $\overline{0}$ & $\begin{array}{l}\overrightarrow{0} \\
0\end{array}$ & $\bar{z}$ & & \\
\hline$\Sigma$ & $\frac{n}{0}$ & 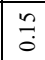 & 7 & 8 & 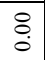 & 8 & $:$ & & & & & & & & & & 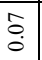 & 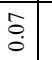 & 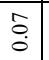 & ó. & $\dot{0}$ & $\begin{array}{l}0 \\
0 \\
0\end{array}$ & : & $\begin{array}{l} \\
0 \\
0\end{array}$ & \\
\hline$z_{n}$ & $\begin{array}{l}f \\
0\end{array}$ & 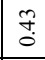 & f & gे & & & $\overbrace{0}^{8}$ & & & & & & & & & & తે & $\overrightarrow{\vec{\partial}}$ & & $\overrightarrow{\text { స్ }}$ & ণิ & $\begin{array}{c}\mid \grave{a} \\
\end{array}$ & તి & iุ & \\
\hline 列 & $\frac{9}{0}$ & 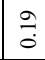 & $\frac{0}{0}$ & $\stackrel{8}{\circ}$ & g & 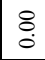 & $\stackrel{8}{\circ}$ & & & & & & & & & & $\stackrel{g}{\partial}$ & $\stackrel{\circ}{\circ}$ & ठे. & $\stackrel{\circ}{\circ}$ & oे & $\begin{array}{l}0 \\
\dot{a} \\
\dot{O}\end{array}$ & $\stackrel{\circ}{\circ}$ & & \\
\hline- & $\stackrel{8}{0}$ & & 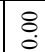 & 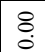 & $\xi$ & $\begin{array}{l}8 \\
0\end{array}$ & $\stackrel{8}{\circ}$ & & & & & & & & $\stackrel{0}{\circ}$ & 0 & $\begin{array}{l} \\
\\
0\end{array}$ & $\begin{array}{ll} \\
\\
0\end{array}$ & $\stackrel{0}{0}$ & 8 & 8 & $\begin{array}{l}8 \\
\end{array}$ & 8 & $\begin{array}{l} \\
\\
0\end{array}$ & \\
\hline U & 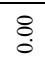 & & 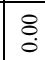 & 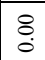 & & 8 & $\stackrel{0}{\circ}$ & & & & & & & & & & 8 & $\stackrel{8}{8}$ & 8 & 8 & $\stackrel{8}{0}$ & 8 & $\stackrel{8}{\circ}$ & $\stackrel{8}{0}$ & \\
\hline P & $g$ & & & & & & & & & & & & & & & & 8 & 8 & 8 & 8 & $\stackrel{8}{8}$ & 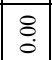 & $\stackrel{8}{0}$ & $\stackrel{8}{0}$ & \\
\hline 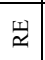 & $\stackrel{8}{\circ}$ & & & 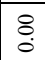 & & & & & & & & & & & & & & & 8 & & & $\stackrel{8}{8}$ & 8 & $\stackrel{8}{0}$ & \\
\hline$\underline{\Delta}$ & 8 & $\xi$ & $\stackrel{8}{8}$ & $\stackrel{8}{8}$ & 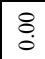 & $\ddot{0}$ & 8 & & & & & & & & & & $\stackrel{0}{\circ}$ & $\begin{array}{l}8 \\
0\end{array}$ & $\stackrel{8}{\circ}$ & 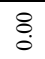 & $\begin{array}{l}8 \\
\end{array}$ & $\begin{array}{l}8 \\
0 \\
\end{array}$ & 8 & & \\
\hline ชี & $\stackrel{8}{\circ}$ & : & $\overbrace{0}^{8}$ & $\frac{8}{8}$ & 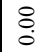 & 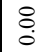 & $\stackrel{8}{8}$ & & & & & & & 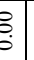 & $\therefore$ & & $\stackrel{8}{0}$ & \begin{tabular}{l|} 
\\
\\
\end{tabular} & $\stackrel{8}{0}$ & $\stackrel{8}{0}$ & $\begin{array}{l}8 \\
\end{array}$ & \begin{tabular}{|l}
8 \\
8
\end{tabular} & $\stackrel{8}{\circ}$ & $\begin{array}{l} \\
\\
\end{array}$ & \\
\hline$\underline{\underline{v}}$ & $\stackrel{0}{0}$ & $\stackrel{0}{0}$ & $\frac{8}{8}$ & $\stackrel{0}{0}$ & $\stackrel{8}{\circ}$ & $\stackrel{8}{\circ}$ & $\stackrel{8}{\circ}$ & & & & & & & 8 & 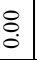 & & $\begin{array}{l}8 \\
\vdots \\
\vdots\end{array}$ & $\begin{array}{l}\vdots \\
\vdots\end{array}$ & $\stackrel{8}{0}$ & $\stackrel{8}{0}$ & $\begin{array}{l} \\
\\
\end{array}$ & \begin{tabular}{|l|l} 
\\
$\vdots$ \\
0
\end{tabular} & $\stackrel{8}{\circ}$ & $\begin{array}{l} \\
\\
\end{array}$ & \\
\hline$E$ & 8 & & $\stackrel{8}{8}$ & \& & & 8 & ¿. & & & & & & & & & & 8 & \begin{tabular}{l|} 
\\
\\
\end{tabular} & 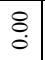 & 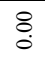 & $\begin{array}{l}8 \\
\end{array}$ & $\begin{array}{l}8 \\
0\end{array}$ & $\stackrel{8}{\circ}$ & $\begin{array}{l} \\
\\
0\end{array}$ & \\
\hline$\vec{n}$ & $\stackrel{8}{0}$ & & $\stackrel{8}{8}$ & $\stackrel{8}{\circ}$ & 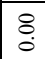 & 10 & 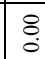 & & & & & & & & & & 0 & $\begin{array}{l}8 \\
: \\
0\end{array}$ & 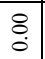 & 0 & $\begin{array}{l}8 \\
0 \\
0\end{array}$ & $\stackrel{8}{8}$ & $\stackrel{8}{\circ}$ & $\stackrel{8}{0}$ & \\
\hline$\sum$ & 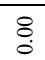 & & 0 & 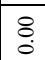 & & 0 & 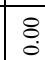 & & & & & & & & & & 0 & $\begin{array}{l}8 \\
0\end{array}$ & $\stackrel{8}{0}$ & 0 & 1.0 & $\begin{array}{l}8 \\
:\end{array}$ & $\stackrel{8}{0}$ & $\begin{array}{l}8 \\
0\end{array}$ & \\
\hline E & 8 & & : & 8 & 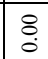 & $\frac{8}{8}$ & 8 & & & & & & & & & & 8 & \begin{tabular}{l|l|}
8 \\
\end{tabular} & $\begin{array}{l}8 \\
0 \\
0\end{array}$ & $\begin{array}{l}8 \\
0\end{array}$ & $\begin{array}{l}8 \\
0\end{array}$ & $\begin{array}{l} \\
0 \\
0\end{array}$ & 8 & $\begin{array}{l} \\
\\
0\end{array}$ & \\
\hline 苋 & 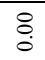 & $\stackrel{8}{\circ}$ & $\stackrel{8}{8}$ & 8 & 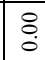 & $\stackrel{8}{\circ}$ & 8 & 8 & & & & & & & 8 & & 8 & $\begin{array}{l} \\
\end{array}$ & $\begin{array}{l}0 \\
0 \\
0\end{array}$ & 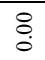 & $\begin{array}{l}8 \\
0\end{array}$ & $\begin{array}{l} \\
0 \\
0\end{array}$ & 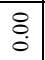 & \begin{tabular}{|l|}
8 \\
0
\end{tabular} & \\
\hline 造 & ¿. & 8 & ¿ & : & $\stackrel{8}{\circ}$ & 8 & : & & & & & & & & & & $\stackrel{8}{0}$ & $\begin{array}{l}8 \\
0 \\
\end{array}$ & $\stackrel{0}{0}$ & $\stackrel{8}{0}$ & $\stackrel{8}{\circ}$ & $\begin{array}{l}0 \\
\vdots \\
0\end{array}$ & $\stackrel{8}{\circ}$ & 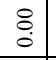 & \\
\hline 畐 & $\begin{array}{l}8 \\
\end{array}$ & 8 & \&. & 8 & $\stackrel{8}{\circ}$ & $\stackrel{0}{\circ}$ & 8 & 0 & & & & & & & 8 & & 8 & $\begin{array}{l} \\
0 \\
0\end{array}$ & $\begin{array}{l} \\
8 \\
0\end{array}$ & 8 & $\begin{array}{l}8 \\
0\end{array}$ & $\begin{array}{l}8 \\
0 \\
0\end{array}$ & 8 & \begin{tabular}{|l|}
8 \\
0
\end{tabular} & \\
\hline \& & 8 & 0 & 8 & 8 & 8 & 8 & $\stackrel{8}{0}$ & & & & & & & & & 0 & $\begin{array}{l} \\
\\
0\end{array}$ & $\begin{array}{l}8 \\
0 \\
0\end{array}$ & \begin{tabular}{l|} 
\\
\\
0
\end{tabular} & $\begin{array}{l}8 \\
0 \\
0\end{array}$ & $\begin{array}{l}8 \\
0\end{array}$ & $\begin{array}{l}8 \\
0\end{array}$ & $\stackrel{8}{0}$ & $\begin{array}{l}8 \\
0\end{array}$ & \\
\hline 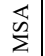 & $\stackrel{8}{\circ}$ & & $\stackrel{8}{8}$ & \&. & $\stackrel{8}{8}$ & 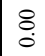 & $\stackrel{8}{\circ}$ & & & & & & & & & & 8 & $\begin{array}{l}8 \\
0\end{array}$ & $\begin{array}{l}8 \\
0 \\
0\end{array}$ & 8 & 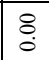 & $\begin{array}{l}8 \\
0 \\
0\end{array}$ & 8 & 8 & \\
\hline & $\stackrel{8}{\circ}$ & & 8 & 8 & & 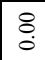 & \& & & & & & & & & & & $\stackrel{8}{0}$ & $\begin{array}{l}8 \\
0 \\
0\end{array}$ & 8 & 8 & 8 & & $\stackrel{8}{\circ}$ & & \\
\hline
\end{tabular}


Summary of the limited matrix:

Table 10. Priority weights and ranking of Product design (PD) with respect RPM, $\mathrm{KM}$, GS, EN, and SCM

\begin{tabular}{|l|c|c|c|c|c|c|c|c|c|c|}
\hline & PD & KM & GS & EN & SCM & PD & KM & GS & ENV & SCM \\
\hline & \multicolumn{9}{|c|}{ Weights } \\
\hline PS & 0.229 & 0.115 & 0.114 & 0.111 & 0.108 & 2 & 2 & 2 & 2 & 2 \\
\hline M & 0.153 & 0.077 & 0.076 & 0.074 & 0.072 & 4 & 4 & 4 & 4 & 4 \\
\hline SN & 0.433 & 0.217 & 0.215 & 0.21 & 0.204 & 1 & 1 & 1 & 1 & 1 \\
\hline EM & 0.185 & 0.093 & 0.092 & 0.09 & 0.087 & 3 & 3 & 3 & 3 & 3 \\
\hline
\end{tabular}

Table 11. Priority weights and ranking of Patient relationship management (PRM) with respect to $\mathrm{PD}, \mathrm{KM}, \mathrm{GS}, \mathrm{EN}$, and $\mathrm{SCM}$

\begin{tabular}{|l|c|c|c|c|c|c|c|c|c|c|}
\hline & PD & KM & GS & EN & SCM & PD & KM & GS & ENV & SCM \\
\hline & \multicolumn{9}{|c|}{ Weights } \\
\hline PS & 0.229 & 0.115 & 0.114 & 0.111 & 0.108 & 2 & 2 & 2 & 2 & 2 \\
\hline M & 0.153 & 0.077 & 0.076 & 0.074 & 0.072 & 4 & 4 & 4 & 4 & 4 \\
\hline SN & 0.433 & 0.217 & 0.215 & 0.210 & 0.204 & 1 & 1 & 1 & 1 & 1 \\
\hline EM & 0.185 & 0.093 & 0.092 & 0.090 & 0.087 & 3 & 3 & 3 & 3 & 3 \\
\hline
\end{tabular}

Ranking of priority weights of product design is consistent across PRM, KM, GS, EN, and SCM: BR $>\mathrm{KM}>\mathrm{TR}$. This implies that investment priorities in designing and management PRM, KM, GS, EN, and SCM should be based on the priority weights of the product design criteria.

Similarly, ranking of priority weights of patient relationship management is consistent across PD, KM, GS, EN, and SCM: $\mathrm{SN}>\mathrm{PS}>\mathrm{EM}>\mathrm{M}$. This is also true for PRM.

\section{Conclusion}

As telemedicine is a multi-discipline health care service a number of dimensions and criteria were used in this study. As the results of this study show that product design and patient relationship management have a higher level of interactions with the rest of the dimensions that were considered in this study. Both dimensions are highly dependent on the rest of the dimensions, i.e., knowledge management, governance structure, environment, and supply chain management.

\section{References}

[1] WHO, (2009). Telemedicine: opportunities and developments in member. States: report on the second global survey on eHealth.

[2] Bahadini K, Yogesan K, Wootton R. (2009). Health staff priorities for the future development of telehealth in Western Australia, Rural Remote Health, 9(3): 1164.

[3] Abdulmajid Asiri et al (2018). ACTA INFORM MED. 26(3):201-206) 
[4] 2015, ARPN Journal of Engineering and Applied Sciences, vol. 10, No. 2.

[5] Sandra da Silva Mattos et al (2015). Bull World Health Organ. 93:881-887

[6] Paul Lillrak, (2015). Small and big quality in health care, International Journal of Health Care Quality Assurance, Vol. 28 Iss 4 pp. 356 - 366. https://doi.org/10.1108/ijhcqa-052014-0068

[7] Hauser, J.R., Klein, R.L. (1988). Without good research, quality is shot in dark. Marketing News 22 (1), 1-2.

[8] Chang, C.H. (1989). Quality function deployment (QFD) processes in an integrated quality information system. Computers and Industrial Engineering 17 (1-4), 311-316. https://doi.org/10.1016/0360-8352(89)90080-6

[9] Antoniac et al, (2014). Design and Development of Mobile Services Platform for Senior Citizens; https://www.researchgate.net/publication/228719509

[10] Mr. Salahuddin (Thesis, 2018) - Quality Function Deployment Method and Its Application on Wearable Technology Product Development, 4-27-2018

[11] Peruzzini and Michele Germani (2014); Designing a user-centered ICT platform for active aging. https://www.researchgate.net/publication/265726320

[12] Compeau et al, (1999); Social cognitive theory and individual reactions to computing technology.

[13] Bandura (1971). Social learning theory; Library of Congress Catalog, Card Number 75170398

[14] M. Rosenstock et al, (1988); Social Learning Theory and the Health Belief Model; Vol. 15(2): 175-183.

[15] Papazoglou et al, (2000); integrated value chains and their implications from a business and technology standpoint; Decision Support Systems. 29, 323-342. https://doi.org/ 10.1016/s0167-9236(00)00081-6

[16] Alt et al, (2003); for Pharma AG; Customer relationship management architecture in the pharmaceutical industry. Int. J. Healthcare Technology and Management, Vol. 5, Nos. $3 / 4 / 5,2003$

[17] Muhammad Anshari 1, and Mohammad Nabil Almunawar (2011); Evaluating CRM Implementation in Healthcare Organization. Proceedings of 2011 International Conference on Economics and Business Information, Bangkok, Thailand, 7-9 May, 2011, pp. xxx-xxx

[18] Rodgers et al (2002). Impact of Technology Sustainability on Healthcare Governance; Proceedings of the 36th Hawaii International Conference on System Sciences (HICSS'03), $0-7695-1874-5 / 03$

[19] Mishra and Chand, (2011); Rodgers et al, 2002; Ramani, 2004; Heeks, 2001; Sharma and Vaisal, 2012; Jenkison, 2010; Nair, 2014;]

[20] Mort et al (2016); Making and Unmaking Telepatients Identify and governance in new health technologies. Sth.sagepub.com vol. 34, No. 1, Jan 2009, 9-33.

[21] Lu et al, (2013). Improving RFID adoption in Taiwan's healthcare industry based on a DEMATEL technique with a hybrid MCDM model. Decision Support Systems 56 (2013) 259-269. https://doi.org/10.1016/j.dss.2013.06.006

[22] Ahmadi et al, (2015). Organizational decision to adopt hospital information system: An empirical investigation in the case of Malaysian public hospitals. in te $\mathrm{rn}$ a $\mathrm{ti}$ o $\mathrm{n}$ a $1 \mathrm{j}$ o u rnal of medicalinformatics 84 ( 2015 ) 166-188

[23] Ali Taghizadeh Herat et al (2012). African Journal of Business Management Vol. 6(2), pp. 627-645.

[24] Tseng, M.-L. (2009a). A causal and effect decision making model of service quality expectation using grey-fuzzy DEMATEL approach; Expert Systems with Applications, 36, 7738-7748 https://doi.org/10.1016/j.eswa.2008.09.011 
[25] Tsai, W. H., \& Chou, W. C. (2009). Selecting management systems for sustainable development in SMEs; A novel hybrid model based on DEMATEL, ANP, and ZOGP; Expert Systems with Applications, 36(2), 1444-1458. https://doi.org/10.1016/j.eswa.2007.11.058

[26] Wu, W. W. (2008); choosing knowledge management strategies by using a combined ANP and DEMATEL approach. Expert Systems with Applications, 35(2), 828-835. https://doi.org/10.1016/i.eswa.2007.07.025

[27] Ming-Lang Tseng; using a hybrid MCDM model to evaluate firm environmental knowledge management in uncertainty. Applied Soft Computing 11 (2011) 1340-1352 https://doi.org/10.1016/j.asoc.2010.04.006

[28] Tzeng et al, (2007). Evaluating intertwined effects in e-learning programs: A novel hybrid MCDM model based on factor analysis and DEM. Expert Systems with Applications 32, 1028-1044. https://doi.org/10.1016/j.eswa.2006.02.004

[29] Yang et al. (2008). A Novel Hybrid MCDM Model Combined with DEMATEL and ANP with Applications. International Journal of Operations Research Vol. 5, No. 3, 160-168.

\section{Author}

Yousif Salim Abdalla, University of Khartoum, School of Business Administration, Department of Business Administration, Khartoum, Sudan, datsunaa@yahoo.com

Article submitted 2019-03-16. Resubmitted 2019-04-26. Final acceptance 2019-04-27. Final version published as submitted by the authors 